\title{
Quantificação e análise do custo da sobra limpa em unidades de alimentação e nutrição de uma empresa de grande porte
}

\section{$\|$}

Quantification and analysis of the cost

of food wastage in the cafeterias of

a large company

Isabel Cristina Cordeiro SOARES ${ }^{1}$

Elizangela Rodrigues da SILVA²

Silvia Eloiza PRIORE ${ }^{2}$

Rita de Cássia Lanes RIBEIRO²

Marina Maria Lelis da Silva PEREIRA ${ }^{3}$

Helena Maria PINHEIRO-SANT'ANA²

\section{RE S U M O}

\section{Objetivo}

O propósito deste estudo foi quantificar e avaliar o custo da sobra limpa em oito unidades de alimentação e nutrição de uma empresa siderúrgica de grande porte.

\section{Métodos}

Foram avaliadas oito unidades de alimentação e nutrição durante cinco meses. A quantificação da sobra limpa considerou as sobras e o número de refeições planejadas e servidas diariamente. As preparações foram divididas em grupos, sendo os custos obtidos a partir do valor médio dos alimentos adquiridos no mês.

\section{Resultados}

Cinquenta por cento das unidades de alimentação e nutrição não atingiram valores inferiores ou iguais a 30g, meta per capita de sobra limpa determinada pela empresa. Os per capitas totais de sobra limpa variaram entre $24 \mathrm{~g}$ e $60 \mathrm{~g}$, equivalentes a $176 \mathrm{~kg}-1.213 \mathrm{~kg}$ de alimentos desperdiçados mensalmente. As saladas apresentaram as maiores porcentagens de desperdício na maioria das unidades. O custo mensal com as sobras atingiu de $2,2 \%$ a $3 \%$ do valor gasto mensalmente com alimentos, representando um custo elevado para a empresa

1 Nutricionista. Viçosa, MG, Brasil.

2 Secretaria de Estado da Saúde de Minas Gerais, Gerência Regional de Saúde. Barbacena, MG, Brasil.

${ }^{3}$ Universidade Federal de Viçosa, Departamento de Nutrição e Saúde. Av. P. H. Rolfs, s/n., Campus Universitário, 36571-000,

Viçosa, MG, Brasil. Correspondência para/Correspondece to: H.M. PINHEIRO-SANT'ANA. E-mail: <helena.santana@ufv.br>. 
594 | I.C.C. SOARES et al.

(entre 80 a 108 salários-mínimos). Diante dos resultados obtidos, foram propostas medidas de intervenção, tais como planejamento e elaboração adequada das preparações, caracterização dos clientes e ações para educação nutricional.

\section{Conclusão}

As unidades de alimentação e nutrição apresentaram considerável perda de alimentos com a sobra limpa. A implementação das intervenções propostas poderá minimizar essa perda. O valor gasto com esse desperdício poderia ser revertido em melhorias nos processos produtivos.

Termos de indexação: Controle de custo. Controle de qualidade. Desperdício de alimento. Serviços de alimentação.

\section{A B S T R A C T}

\section{Objective}

The purpose of this study was to quantify and assess the cost of food wastage in eight cafeterias of a big steel mill.

\section{Methods}

Eight cafeterias were followed during five months. Quantification of food wastage was done considering the leftovers and the number of meals planned and served daily. For determining the cost, preparations were divided into groups, and the cost was obtained from the average price of foodstuffs purchased during the month.

\section{Results}

Fifty percent of the cafeterias did not achieve wastage less or equal to $30 \mathrm{~g}$ (the per capita food wastage goal set by the company). The total per capita food wastage ranged from $24 \mathrm{~g}$ to $60 \mathrm{~g}$, equivalent to $176-1213 \mathrm{~kg}$ of food wasted monthly. Salads were wasted more often in most foodservices. The monthly cost of food wastage reached $2.2 \%$ to $3.0 \%$ of the amount spent monthly on food. It represented a high expense for the foodservice (approximately 80-108 minimum wages). The results allowed the proposal of intervention measures such as planning and development of appropriate preparations, identification of customers, and nutrition education actions.

\section{Conclusion}

The cafeterias presented considerable food wastage, hence money loss. Implementation of interventions can minimize these losses. Savings from reducing wasteful spending could be used for improving production processes.

Indexing terms: Cost ontrol. Qualidad control. Food wastefulness. Food service.

\section{N T R O D U Ç Ã O}

O setor de alimentação coletiva é um mercado em plena ascensão e vem se tornando representativo na economia brasileira, visto que apresenta faturamento de aproximadamente 9,5 bilhões de reais anuais, sendo responsável pela produção de 8,3 milhões de refeições diárias. Além disso, o segmento oferece 180 mil empregos diretos e representa para os governos uma receita de um bilhão de reais por ano, entre impostos e contribuições. Apesar dos números significativos, estima-se que o potencial teórico de refeições coletivas no Brasil seja superior a 40 milhões de unidades diárias ${ }^{1}$.

O conceito de qualidade vem sendo difundido amplamente e atinge setores que tradicionalmente não se preocupavam com tais questões, como o de produção de refeições coletivas em Unidades de Alimentação e Nutrição (UAN). A busca contínua pela qualidade nesse setor é recente, sendo consequência das próprias exigências do mercado e do cliente, além da mudança do paradigma de que qualidade gera custo ${ }^{2}$.

Em uma UAN há vários tipos de controles específicos que podem ser desenvolvidos visando 
à manutenção do padrão de qualidade, desde a recepção da matéria-prima até a distribuição dos alimentos, incluindo o controle de custos, quantidade, qualidade, níveis de estoque, prazos, características dos produtos e serviços, higiene, entre outros. Entre as informações necessárias para o efetivo controle e avaliação do desempenho da empresa moderna, a mensuração das perdas e das atividades que não agregam valor aos produtos é uma das mais importantes ${ }^{3}$. Por meio da identificação dessas perdas, é possível detectar práticas que geram aumento dos gastos e, em contrapartida, propor mecanismos que levem ao cumprimento das metas estipuladas de acordo com a realidade de cada UAN 4 .

O termo "desperdício" embute o conceito de prejuízo e tem sido uma constante preocupação dos gestores de empresas ${ }^{5}$. Segundo $\mathrm{Vaz}^{6}$, desperdiçar é o mesmo que extraviar; esse extravio poderia ser utilizado para beneficiar pessoas carentes, uma empresa ou a própria natureza. A busca pela qualidade e otimização de recursos, associada à saúde financeira e tecnológica da empresa moderna, opõe-se obviamente às perdas, que geram custo extra, perda de competitividade e diminuição de lucro, ou seja, interferem de modo negativo na imagem de qualquer empreendimento ${ }^{5}$.

Os desperdícios em UAN podem ocorrer em todo o processo de produção de refeições, especialmente no armazenamento, pré-preparo, cocção e distribuição, incluindo a matéria-prima e outros recursos como água, energia e mão de obra $^{6}$. Destaca-se que o desperdício proveniente das sobras de alimentos engloba os alimentos preparados e não distribuídos, comumente denominados de Sobra Limpa (SL) ou resto: aquilo que foi distribuído e não foi consumido? .

No gerenciamento de uma UAN, o desperdício é um fator de grande relevância, uma vez que está ligado diretamente aos custos do estabelecimento ${ }^{8}$. Assim, aprimorar a eficiência do sistema alimentar, visando à prevenção, à diminuição ou até mesmo à eliminação das perdas é primordial para garantir a sobrevivência das empresas no mercado atual'.
Contudo, ressalta-se que o desperdício não deve ser avaliado apenas sob o ponto de vista econômico. Felizmente, percebe-se o crescente interesse das UAN nas questões referentes à responsabilidade socioambiental, tendo em vista a problemática do impacto da geração de resíduos e a necessidade de novas perspectivas de gerenciamento, além da utilização racional dos recursos naturais ${ }^{10}$. Nesse contexto, salienta-se que limitar as perdas de alimentos a fim de diminuir a demanda de recursos naturais proveniente do setor alimentício e alcançar a segurança alimentar serão ainda mais significantes no futuro, visto que esse setor tende a produzir maior número de refeições com o decorrer dos anos ${ }^{11}$.

Dessa forma, controlar o desperdício em UAN é extremamente importante, por se tratar de uma questão não somente econômica e ambiental, mas também político-social no desempenho profissional do nutricionista, tendo em vista que o Brasil é um país onde a subnutrição pode ser considerada um sério problema de saúde pública ${ }^{12}$.

A quantificação da SL constitui indicador que permite detectar falhas na determinação do número de refeições a serem servidas, no superdimensionamento dos per capitas e porções e na aceitação das preparações ${ }^{13}$. Dessa forma, esse indicador pode ser utilizado como subsídio para implementar medidas de racionalização, otimização da produtividade e redução dos custos com o desperdício. O controle da SL pode ser feito por meio da pesagem, juntamente com o cálculo do número de refeições preparadas e do número de refeições servidas ${ }^{12}$.

O custo mensal de uma UAN é obtido pelo somatório das despesas, incluindo a SL, que traz, por si só, uma parcela dos custos agregados em cada etapa do processo de produção: custo de matéria-prima, tempo, energia, mão de obra e equipamentos, o que evidencia seu efeito significativo sobre os resultados financeiros ${ }^{14}$.

Considerando o impacto negativo do desperdício no gerenciamento de UAN e a escassez de estudos nessa área, o objetivo deste trabalho 
596 | I.C.C. SOARES et al.

foi quantificar e avaliar o custo da SL em oito UAN de uma empresa siderúrgica de grande porte, bem como sugerir intervenções de acordo com os resultados, de maneira a alertar os responsáveis na tomada de decisões para a redução dos desperdícios.

\section{MÉTODOS}

O estudo foi realizado em oito UAN localizadas na área interna de uma grande empresa do ramo de siderurgia e geridas por uma concessionária do setor alimentício. As UAN avaliadas foram nomeadas por códigos em ordem alfabética de $\mathrm{A}-\mathrm{H}$.

As oito UAN servem diariamente $18 \mathrm{mil}$ refeições, distribuídas em desjejum, almoço, jantar 1 e 2, lanche 1 e lanche 2, e contam com uma equipe de 340 colaboradores em três turnos. A clientela atendida é composta por funcionários de ambos os sexos que desenvolvem atividades de intensidade leve a pesada.

O serviço prestado é descentralizado, e as refeições são preparadas na UAN central (A) e, posteriormente, distribuídas para as demais, que apenas finalizam algumas das preparações e realizam a distribuição. O sistema de distribuição de refeições é do tipo self service parcial, sendo as opções de prato proteico e a sobremesa porcionadas por funcionários das unidades.

A pesquisa incluiu dados coletados nos meses de janeiro a maio de 2005.

\section{Meta e cálculo da sobra limpa}

A meta de SL determinada pela empresa é de valores inferiores ou iguais a $30 \mathrm{~g}$ per capita por preparação. Para cálculo da SL, avaliaram-se e correlacionaram-se os dados da SL com o número de refeições planejadas e servidas diariamente em cada UAN.

A pesagem da SL é realizada como rotina em cada unidade após a distribuição do almoço, jantar 1 e jantar 2. As sobras das preparações são pesadas separadamente e esses valores são registrados e comparados aos valores de refeições servidas.

Assim, o Cálculo do per capita da Sobra Limpa (CSL) foi efetuado pela seguinte equação: $C S L=X Y$

Em que:

$X:$ total de sobra limpa em kg;

Y: número de refeições servidas.

Os dados obtidos e compilados diariamente auxiliam no controle da produção e distribuição dos alimentos, de maneira a se obter o número total de refeições mensais, a quantidade de SL total por UAN e seu per capita médio.

\section{Determinação do custo da sobra limpa}

O cálculo do custo da SL baseou-se apenas nos gastos com a matéria-prima. Apurou-se o custo do principal ingrediente de cada preparação, não tendo sido incluídos os valores despendidos com sal, óleo e outros temperos.

Para o cálculo do custo da SL, realizou-se a conversão do peso pronto dos alimentos para o peso cru, considerando o rendimento e os fatores de correção e cocção de cada preparação. As preparações foram divididas nos seguintes grupos: arroz, feijão, guarnição, prato proteico e salada. Para cada grupo, calcularam-se os valores médios para o per capita (peso cru), rendimento, porção e custo por porção.

Por exemplo, o valor per capita do arroz é $0,109 \mathrm{~kg}$, rendimento de 2,3 e a porção é 0,251 kg. O custo do per capita e da SL para cada grupo de preparação foi obtido por meio do valor médio de todos os ingredientes da preparação adquiridos no mês. A atualização dos valores foi realizada mensalmente. Nesse caso, o custo médio do per capita de arroz $(0,109 \mathrm{~kg})$ é de $\mathrm{R} \$ 0,15$.

O custo da SL por preparação foi calculado pela seguinte equação: Custo da $S L=\{(P C S)$ / $(P C)\} \times(C P C)$ 
Em que:

PCS = peso cru da sobra por preparação em kg (peso da SL pronta, em kg / rendimento da preparação);

PC = per capita da preparação em kg;

CPC = custo médio per capita da preparação crua em reais;

Exemplo do custo da SL de arroz em um determinado dia:

peso da SL pronta $=10,9 \mathrm{~kg}$; rendimento $=2,3$;

per capita =0,109kg; custo do per capita $=\mathrm{R} \$ 0,15$;

PCS $=10,9 \mathrm{~kg} / 2,3=4,74$;

custo da $S L=4,74 / 0,109 \times 0,15=R \$ 6,52$.

\section{RESULTADOS}

Os valores médios para o per capita de SL das oito UAN no período avaliado estão apresentados na Figura 1.
As UAN D, E, G e H não atingiram, no período de janeiro a maio de 2005, valores inferiores ou iguais a $30 \mathrm{~g}$ per capita de SL, como determinado pela empresa. Os valores SL per capita variaram de 33 a 54g, 40 a $46 \mathrm{~g}$ e 34 a $51 \mathrm{~g}$ nas UAN D, E e G respectivamente. A UAN A apresentou SL de $27 \mathrm{~g}$ per capita em maio, o único mês no qual foi atingido o valor estipulado. Verificou-se, durante o mês de março, a mesma situação na UAN $C$.

Os melhores resultados foram obtidos pelas UAN B e F, cujas metas foram alcançadas no período de janeiro a abril; na UAN F, os per capitas foram inferiores aos da UAN B.

As saladas foram as preparações que se destacaram com maiores porcentagens de desperdício na maioria das UAN (Figura 2). Verifica-se que em todos os meses analisados, pelo menos 50\% das unidades apresentaram desperdício maior nesse grupo de alimentos. O custo do desperdício com a SL variou de 2,2 a 3\% do valor gasto com gêneros alimentícios (Tabela 1).

O menor custo mensal da SL foi observado no mês de fevereiro ( $R \$ 20.715,00)$; em con-

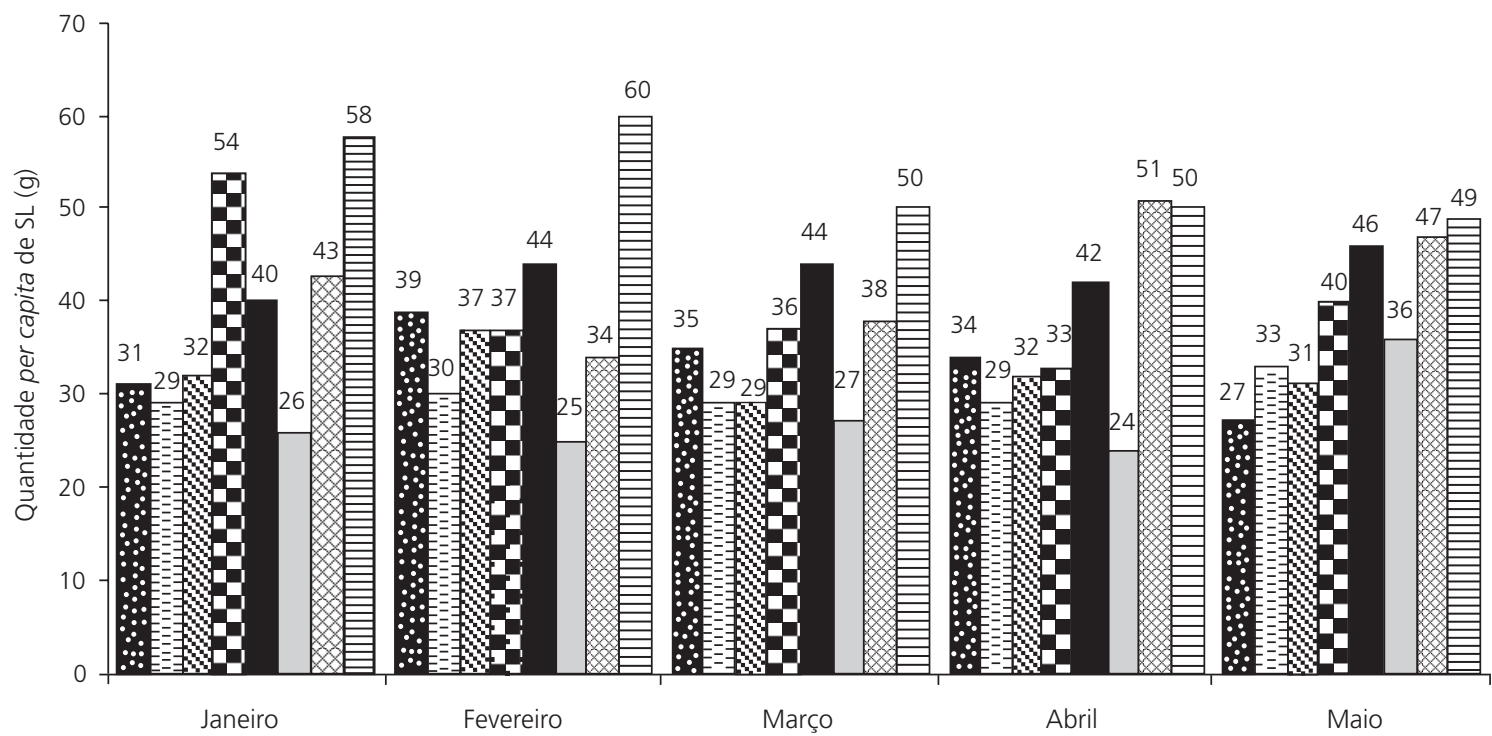

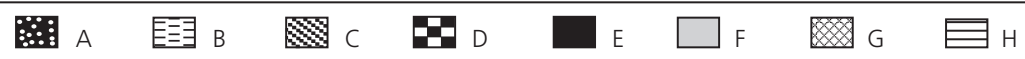

Figura 1. Per capita médio de sobra limpa das UAN avaliadas no período de janeiro a maio. Ipatinga (MG), 2005 
Tabela 1. Comparação entre o custo mensal da sobra limpa no período de janeiro a maio e a meta preconizada pela empresa. Ipatinga (MG), 2005

\begin{tabular}{lcccc}
\hline Mês & $\begin{array}{c}\text { Custo mensal } \\
\text { da SL1 }(R \$)\end{array}$ & $\begin{array}{c}\text { Representação em SM² } \\
\text { custo mensal da SL }\end{array}$ & $\begin{array}{c}\text { Custo mensal da SL } \\
\text { segundo meta da empresa } \\
\text { (30g per capita) (R\$) }\end{array}$ & $\begin{array}{c}\text { Representação em SM }{ }^{\mathbf{2}} \text { do custo } \\
\text { mensal da SL segundo meta da } \\
\text { empresa (30g per capita) }\end{array}$ \\
\hline Janeiro & $25.193,26$ & 96,9 & $18.851,00$ & 72,5 \\
Fevereiro & $20.715,00$ & 79,7 & $16.145,36$ & 62,1 \\
Março & $23.435,67$ & 90,1 & $19.397,14$ & 74,6 \\
Abril & $25.290,13$ & 97,3 & $17.980,27$ & 69,2 \\
Maio & $28.133,84$ & 108,2 & $20.706,21$ & 79,6 \\
Média & $24.553,58$ & 94,4 & $18.615,99$ & 71,6 \\
\hline Projeção do CA & $294.642,96$ & $1.133,2$ & $223.391,88$ & 859,2 \\
\hline
\end{tabular}

1SL: sobra limpa; ${ }^{2 S M}$ : salário-mínimo; considerando o valor do SM no período do estudo de R\$ 260,00; ${ }^{3} \mathrm{CA}$ : custo anual.

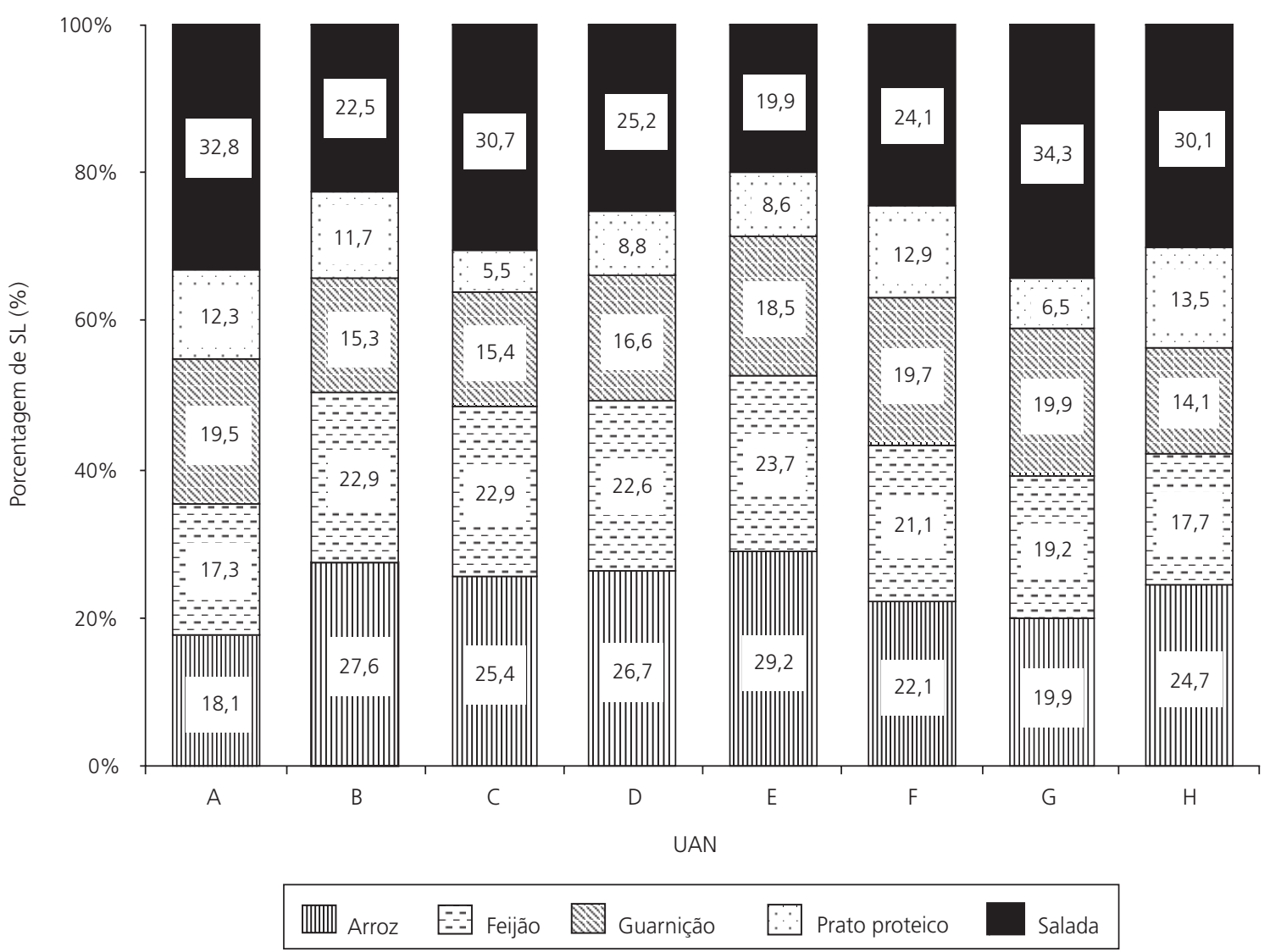

Figura 2. Composição da sobra limpa fragmentada por grupos de preparações, obtida nas UAN no período de janeiro a maio. Ipatinga (MG), 2005

trapartida, em maio, foi registrado o maior valor ( $R \$ 28.133,84)$. O custo de $30 \mathrm{~g}$ de SL oscilou durante os cinco meses estudados (janeiro a maio), uma vez que esse valor pode sofrer influência do custo da matéria-prima no período calculado e do número de clientes. Verificou-se redução dos custos nos meses de fevereiro e abril e aumento nos meses de março e maio. Durante o período 
de janeiro a maio, a UAN G apresentou o maior custo com a SL. Já o menor custo foi verificado na UAN F, cujo percentual de SL foi inferior às demais UAN avaliadas (Tabela 2).

A Tabela 3 mostra o custo per capita da SL de cada UAN, fragmentado por grupo de preparações. Os valores foram obtidos por meio da relação entre o custo da SL total e a quantidade de refeições servidas mensalmente em cada UAN.

\section{I S C U S S Ã O}

No Brasil, observa-se um imenso paradoxo: a coexistência do desperdício de alimentos e a fome $^{15}$. Esse desperdício torna-se evidente e significativo nos setores produtores de alimentos e pode ser observado na devolução das bandejas de refeições, no lixo e até mesmo na falta de indicadores de qualidade².
Segundo Associação Brasileira de Restaurantes e Empresas de Entretenimentos (ABRASEL) ${ }^{16}$, o estabelecimento que possui controle rigoroso de sua cozinha descarta cerca de $15,0 \%$ do que é preparado para atender a clientela, o que corresponde a aproximadamente $5,0 \%$ do faturamento bruto. Contudo, pode-se perder até 50,0\% do que é preparado, o equivalente a $15,0 \%$ do faturamento do mês. Nesse contexto, justifica-se a importância de estudos in loco, visando a identificar e a propor alternativas para o controle desses gastos.

No presente estudo, $50 \%$ das UAN não atingiram valores iguais ou inferiores a $30 \mathrm{~g}$ per capita de SL, como preconizado pela empresa. Os per capitas totais de SL variaram entre $24 \mathrm{~g}$ e $60 \mathrm{~g}$, o que corresponde a uma faixa de $176 \mathrm{~kg} \mathrm{a}$ $1213 \mathrm{~kg}$ de alimentos jogados no lixo mensalmente. Marques et al. ${ }^{4}$, em trabalho similar que avalia o atendimento da meta de $30 \mathrm{~g}$ per capita

Tabela 2. Custo médio da sobra limpa total fragmentada por unidades de alimentação e nutrição no período de janeiro a maio de 2005. Ipatinga (MG), 2005.

\begin{tabular}{lcc}
\hline UAN & Custo total da L $^{1}(\mathrm{R} \$)$ & Representação em $\mathrm{SM}^{2}$ do custo total da SL \\
\hline A & $5.880,59$ & 22,61 \\
B & $2.277,12$ & 8,76 \\
C & $2.802,52$ & 10,78 \\
D & $2.056,86$ & 7,91 \\
E & $1.635,58$ & 6,29 \\
F & 442,91 & 1,70 \\
G & $7.386,54$ & 28,41 \\
H & $2.651,46$ & 10,20 \\
\hline
\end{tabular}

1SL: sobra limpa; ${ }^{2}$ SM: salário-mínimo; considerando o valor do SM no período do estudo de $\mathrm{R} \$ 260,00$.

Tabela 3. Custo $(R \$)$ per capita médio de sobra limpa das unidades de alimentação e nutrição fragmentada por grupo de alimentos no período de janeiro a maio. Ipatinga (MG), 2005.

\begin{tabular}{lccccc}
\hline UAN & Arroz & Feijão & Guarnição & Prato principal & Salada \\
\hline A & 0,004 & 0,002 & 0,009 & 0,020 & 0,060 \\
B & 0,005 & 0,003 & 0,006 & 0,020 & 0,040 \\
C & 0,005 & 0,003 & 0,006 & 0,008 & 0,050 \\
D & 0,006 & 0,003 & 0,080 & 0,020 & 0,052 \\
E & 0,008 & 0,004 & 0,011 & 0,020 & 0,040 \\
F & 0,004 & 0,002 & 0,005 & 0,020 & 0,030 \\
G & 0,005 & 0,003 & 0,010 & 0,010 & 0,080 \\
H & 0,023 & 0,004 & 0,010 & 0,040 & 0,090 \\
\hline
\end{tabular}

UAN: unidades de alimentação e nutrição. 
de SL por refeição e que analisa a quantidade e o custo da SL em 8 restaurantes, verificaram que nenhum dos restaurantes avaliados apresentou frequência de atendimento igual ou inferior a $100,0 \%$ da meta preconizada, sendo registrado desperdício total de aproximadamente 7 toneladas de alimentos. Pedro \& Claro ${ }^{9}$, ao analisar a gestão de perdas em um restaurante popular, reportaram SL diária de aproximadamente 2,5\% do total produzido, sendo considerados no estudo apenas os gêneros alimentícios do prato base oferecidos no almoço (arroz, feijão, prato principal e guarnição). Segundo os autores, embora fosse mantido o mesmo número de clientes atendidos, ocorreram variações consideráveis em relação ao índice de SL encontrado. Ricarte et al. ${ }^{17}$ encontraram média de desperdício de SL referente a hortaliças e frutas de aproximadamente 7,0\% da quantidade produzida por dia em um restaurante universitário, e observaram variações bastante acentuadas nos índices encontrados em 7 dias dos 14 avaliados.

Estudo conduzido por Engström \& Carlsson-Kanyama ${ }^{11}$, que avaliou o desperdício de alimentos desde o recebimento da matéria-prima até o consumidor final em duas instituições escolares e dois restaurantes comerciais, revelou perdas importantes de alimentos, uma vez que, em média, 20\% dos alimentos entregues a esses estabelecimentos foram descartados, entretanto, a metade das perdas registradas foi proveniente do resto-ingestão. Os autores enfatizaram que reduzir a perda de alimentos é uma importante medida para superar a fome e minimizar os impactos ambientais provenientes do sistema alimentar.

Entre as oito UAN avaliadas, observou-se que as unidades $D, E, G$ e $H$, que têm maiores porcentagens de clientes que realizam atividade intensa, apresentaram valores per capitas médios de SL mais elevados. Em contrapartida, o menor percentual de SL encontrado na UAN F é decorrente principalmente das peculiaridades observadas para a clientela atendida nessa unidade, uma vez que $95 \%$ dela desenvolvem atividades administrativas - atividade leve -, têm maior grau de instrução e nível socioeconômico, fatores que podem ter influenciado a quantidade de SL gerada e, consequentemente, o menor custo referente a essas sobras.

$V_{a z}{ }^{6}$ afirma que o percentual de SL pode sofrer variações consideráveis de um restaurante para outro, sendo necessário apurar valores no próprio estabelecimento, visando a reduzir as sobras a um valor aceitável. Diante das diferentes características detectadas nas UAN, torna-se imprescindível estabelecer metas de SL compatíveis com cada unidade, considerando suas peculiaridades. Para tanto, é interessante envolver toda a equipe de colaboradores da UAN, com o intuito de traçar metas tangíveis de controle de sobras, realizar capacitação e conscientização da equipe e, sempre que possível, preparar os alimentos em etapas, de acordo com a demanda ${ }^{18}$.

Entre os grupos de alimentos avaliados neste estudo, as saladas foram as preparações que mais contribuíram com o desperdício. Essa mesma observação foi feita por Engström \& Carlsson-Kanyama ${ }^{11}$, que também constataram que as saladas eram o alvo do desperdício nos restaurantes comerciais avaliados, enquanto nas escolas as preparações contendo batatas, arroz, e massas apresentavam as maiores porcentagens.

Evidenciou-se que as saladas disponíveis no cardápio se mantiveram no mesmo padrão de corte e não foram acrescidas de outros ingredientes para sua diferenciação. A repetição de alguns alimentos foi claramente notada e justificada pela baixa qualidade dos produtos no mercado, que resultava em trocas frequentes de algum componente, e que culminou na redução da aceitação da preparação.

A baixa variação nos cortes e a falta de padronização das saladas foram também detectadas. Observou-se pequena frequência de saladas compostas e mistas e a maioria delas era servida crua. Esporadicamente houve a oferta de frutas como um dos componentes das saladas (por exemplo: repolho com abacaxi; pepino, repolho e maçã) e saladas com molho e cremes. Segundo 
Proença et $a / .{ }^{19}$, a variedade de hortaliças e ingredientes pode contribuir para aguçar o interesse no consumo da preparação.

Embora não se tenha encontrado grande proporção de itens nas saladas com cores semeIhantes, não foi demonstrada a preocupação por parte das UAN com a disposição dos gastronormes nos balcões de distribuição, considerando as cores das hortaliças e suas combinações. Veiros ${ }^{20}$ relatou que a semelhança das cores dos alimentos oferecidos acarreta a monotonia visual, que, por sua vez, pode interferir na escolha dos alimentos, aceitação e na satisfação dos clientes com a refeição.

Percebeu-se que algumas UAN adotam a decoração das saladas com o objetivo de incentivar seu consumo, porém ela não é mantida durante todo o atendimento. Nos estudos de Veiros ${ }^{20}$ e Veiros \& Proença ${ }^{21}$, os autores preocuparam-se em verificar a apresentação dos pratos pela importância visual do alimento oferecido, visando a estimular seu consumo.

O uso de decoração nas preparações, a adição de ingredientes com cores contrastantes e o cuidado no posicionamento das preparações no balcão de distribuição, buscando a combinação das cores, são estratégias que apontam para bons resultados no tocante à estimulação do consumo e à redução da SL. Proença et al. ${ }^{19}$ ressaltam que mesmo os clientes que não possuem o hábito de consumir saladas podem ser atraídos pela decoração e apresentação dos pratos.

A utilização de gastronormes ou travessas menores pode viabilizar a oferta das saladas com reposição frequente, garantindo maior segurança e um melhor aspecto visual. O uso de utensílios e vasilhames atrativos ao cliente também favorece a aceitação das preparações ${ }^{12}$. Diversos autores relatam que a apresentação e a aparência das preparações influenciam diretamente a aceitação do prato pelo cliente 22-24. $^{22}$.

Nas oito UAN avaliadas, as saladas são oferecidas com o tempero à parte para escolha do cliente. Os temperos disponibilizados incluem azeite composto (85\% de óleo de soja e 15\% de azeite de oliva), vinagre, sal, molho inglês, molho para salada à base de legumes, molho quente à base de carne, molho de pimenta e três tipos de pimenta (malagueta, cumarim e de bode). Notou-se a baixa variedade dos ingredientes que compõem o molho para salada. Sugerir ao cliente formas diversas de temperar a salada e diversificar os tipos de molhos para essas preparações poderia contribuir para aumentar seu consumo e evitar sobras.

Apenas nas unidades A, B, C, F, G e H as saladas servidas eram dispostas em balcão de distribuição frio. A temperatura das saladas é outro fator que influencia diretamente sua aceitação. Assim, o monitoramento da temperatura das preparações e equipamentos (pass through refrigerado, geladeira e balcão de distribuição) torna-se indispensável para a manutenção da qualidade do produto e controle do desperdício ${ }^{25}$.

Embora a empresa preconize a meta de $30 \mathrm{~g}$ de SL per capita, verificou-se que essa quantidade já representa custo elevado. O gasto com o desperdício poderia ser revertido na implementação de inovações na produção das refeições, como equipamentos, produtos alimentícios e processos produtivos. Esses investimentos poderiam trazer melhorias na qualidade das refeições, nas condições de trabalho e na produtividade, com consequente reflexo na competitividade da empresa.

No presente estudo, a projeção do custo anual com a SL nas UAN avaliadas atingiu um valor de $R \$ 294.642,96$. Um alto custo também foi verificado em estudo que avaliou o desperdício de alimentos em um restaurante universitário (perda monetária de $\mathrm{R} \$ 157.586,00$ ao ano). De acordo com os autores, esse custo representa $12,3 \%$ dos gastos com aquisição de matéria-prima de gêneros alimentícios no restaurante ${ }^{26}$. Pedro \& Claro $^{9}$ observaram, em apenas 13 dias de estudo, custo elevado com SL: R\$1237,28. Marques et al. ${ }^{4}$ relataram que o custo da SL total foi de $R \$ 18.451,00$ durante o período do estudo; desse valor, o almoço representou 79,9\%, o jantar $10,3 \%$ e a ceia $9,8 \%$. Os custos da SL per capita 
não sofreram grandes variações durante o período avaliado. Verificou-se que, na maioria dos meses em estudo, o custo per capita referente ao grupo das saladas foi superior em quase todas as UAN, uma vez que essas preparações se destacaram como o grupo de alimentos que mais contribuiu com o desperdício nessas unidades.

A gestão dos recursos de forma eficiente e a redução de perdas no processo produtivo são fontes de diminuição dos custos $^{27}$, portanto os gastos relacionados ao desperdício são bastante significativos para a empresa estudada, uma vez que o contrato da concessionária com a contratante é do tipo preço fixo, acarretando menor lucro por parte da empresa contratada. O sucesso e a continuidade de qualquer empresa no mercado dependem dos resultados positivos (lucros) que elas possam gerar durante suas atividades operacionais.

Em todas as UAN, o controle das sobras bem como dos seus custos efetivos devem ser acompanhados e geridos adequadamente. Assim, a partir das características verificadas nas UAN avaliadas, foram propostas medidas a fim de reduzir a SL gerada e, como consequência, minimizar os custos e os impactos ambientais. Implementadas de forma continuada, as medidas de intervenção devem:

- Realizar diariamente o planejamento adequado da quantidade das preparações, baseando-se no número de refeições servidas, a fim de evitar excessos de produção;

- Capacitar os funcionários da UAN para que possam estar atentos quanto à apresentação e à decoração das preparações, limpeza dos balcões de distribuição, mesas e salões, técnicas de atendimento ao cliente e cuidados na reposição dos pratos;

- Garantir que as preparações sejam disponibilizadas em vasilhames e utensílios visualmente atrativos ao cliente e devidamente higienizados;

- Desenvolver e implementar na empresa capacitação referente a novos tipos de cortes de vegetais, visando melhorar a apresentação das saladas;

- Estimular a equipe operacional a realizar a degustação das preparações, procurando estabelecer uma avaliação das características sensoriais, envolvendo aspectos como sabor, aroma, textura e aparência;

- Implementar cursos de capacitação à equipe operacional que incluam a temática de técnicas culinárias, com avaliação periódica;

- Oferecer opções variadas de molhos com o intuito de melhorar a palatabilidade dessas preparações e aumentar seu consumo e informar os clientes sobre a forma de utilização dos temperos para as saladas;

- Realizar atividade de educação nutricional para os clientes, visando a incentivar o consumo de saladas por meio de folhetos explicativos com recomendações do consumo diário de fibras, vitaminas e minerais, além de destacar as principais fontes alimentares e a importância desses nutrientes para a saúde;

- Verificar, por meio de pesquisa de satisfação, a preferência dos clientes em relação às técnicas de preparo das saladas, tipos de vegetais e cortes;

- Adequar a refrigeração dos balcões de distribuição daqueles que não a possuem e monitorar frequentemente a temperatura dos equipamentos de armazenamento e distribuição, a fim de garantir a temperatura adequada e segura para as preparações;

- Melhorar os critérios de seleção dos fornecedores de hortaliças e frutas, visando à aquisição de produtos de alta qualidade.

C O N CLUS Ã O

Verificou-se que $50 \%$ das UAN avaliadas não atingiram valores inferiores ou iguais a $30 \mathrm{~g}$ de SL per capita preconizados pela empresa. Os per capitas totais de SL variaram entre 24 e $60 \mathrm{~g}$. As saladas destacaram-se como as preparações 
que apresentaram as maiores porcentagens de desperdício e custo per capita na maioria das UAN durante o período em estudo.

O custo total com a SL no período de estudo foi elevado, totalizando $\mathrm{R} \$ 24.553,58(94,4$ salários-mínimos) em desperdícios.

Os resultados apontam consideráveis perdas de alimentos - além da perda monetária que podem afetar negativamente a produtividade, o lucro e o desempenho competitivo das UAN no mercado. Soma-se a isso a preocupação com o impacto socioambiental que pode ser gerado como consequência desses desperdícios.

Destaca-se, assim, a necessidade de intervenções mais eficazes na elaboração das refeições, tais como o planejamento e a elaboração adequada das preparações, a caracterização dos clientes, além de ações para educação nutricional.

O valor gasto com o desperdício poderia ser investido na aquisição de novos equipamentos, produtos alimentícios e melhorias nos processos produtivos.

\section{COLABORADORES}

I.C.C. SOARES participou da execução da pesquisa e redação do artigo científico, E.R. SILVA e M.M.L. SILVA participaram da redação do artigo científico, S.E. PRIORE e R.C.L. RIBEIRO participaram da concepção do projeto, orientação da coleta e interpretação dos dados; H.M. PINHEIRO-SANT'ANA participou da concepção do projeto, orientação da coleta, interpretação dos dados, redação e revisão do artigo científico.

\section{REFERÊ N CIAS}

1. Associação Brasileira das Empresas de Refeições Coletivas. Bol ABERC Not [Internet]. 2009 [acesso 2009 jul 15]. Disponível em: <http://www.aberc. com.br/Uploads/pdfs/Jornal_ABERC-109.pdf>.

2. Bradacz D. Modelo de gestão da qualidade para o controle de desperdício de alimentos em unidades de alimentação e nutrição [mestrado]. Florianópolis: Universidade Federal de Santa Catarina; 2003.

3. Proença RPC. Inovação tecnológica na produção de alimentação coletiva. Florianópolis: Insular; 2000.
4. Marques ES, Coelho AIM, Horst S. Controle de sobra limpa no processo de produção de refeições em restaurantes. Hig Aliment. 2008; 22(160):20-4.

5. Gonçalves BS, Magri C, Forlenza KB, Silva LF, Mirra $\mathrm{M}$, Itacarambi P. O compromisso das empresas com o combate ao desperdício de alimentos: Banco de alimentos, colheita urbana e outras ações. São Paulo: Instituto Ethos; 2005.

6. Vaz CS. Restaurantes: controlando custos e aumentando lucros. Brasília: Metha; 2006.

7. Teixeira SMF, Oliveira ZMC, Rego JC, Biscontini TMB. Administração aplicada às unidades de alimentação e nutrição. São Paulo: Ateneu; 1990.

8. Vanin M, Novello D. Avaliação do desperdício no pré-preparo de saladas em uma unidade de alimentação e nutrição. Rev Salus-Guarapuava. 2008; 2(2):51-62.

9. Pedro MMR, Claro JACS. Gestão de perdas em unidade de Restaurante Popular: um estudo de caso em São Vicente. Qualit@s Rev Eletr. 2010; 9(1): $1-10$.

10. Kinasz TR, Werle HJS. Produção e composição física de resíduos sólidos em alguns serviços de alimentação e nutrição, nos municípios de Cuiabá e Várzea Grande, Mato Grosso: questões ambientais. Hig Aliment. 2006; 20(144):64-71.

11. Engström R, Carlsson-Kanyama A. Food losses in food service institutions examples from Sweden. Food Policy. 2004; 29:203-13. doi: 10.1016/j.foodpol. 2004.03.004.

12. Ribeiro ACM, Silva LA. Campanha contra o desperdício de alimentos em uma unidade de alimentação e nutrição de Curitiba. Rev Nutr Brasil. 2003; 2(6): 329-36.

13. Hong W, Kirk $D$. The analysis of edible plate waste results in 11 hospitals in the UK. J Food Serv Syst. 1995; 8:115-23. doi: 10.1111/j.1745-4506.1995.tb 00081.x.

14. Hirschbruch MD. Unidades de alimentação e nutrição: desperdício de alimentos $X$ qualidade da produção. Hig Aliment. 1998; 12(55):12-4.

15. Gondim JAM, Moura MFV, Dantas AS, Medeiros RLS, Santos KM. Composição centesimal e de minerais em cascas de frutas. Ciênc Tecnol Aliment. 2005; 25(4):825-7.

16. Associação Brasileira de Restaurantes e Empresas de Entretenimento de Santa Catarina [Internet]. 2002 [acesso 15 jun 2010]. Disponível em: <http:// www.abrasel.com.br>.

17. Ricarte MPR, Fé MABM, Santos IHVS, Lopes AKM. Avaliação do desperdício de alimentos em uma unidade de alimentação e nutrição institucional em Fortaleza-CE. Saber Cient. 2008; 1(1):158-75. 
18. Augustini VCM, Kishimoto P, Tescaro TC, Almeida FQA. Avaliação do índice de resto-ingesta e sobras em unidade de alimentação e nutrição de uma empresa metalúrgica na cidade de Piracicaba/SP. Rev Simbio-Logias. 2008; 1(1):99-110.

19. Proença RPC, Sousa AA, Veiros MB, Hering B. Qualidade nutricional e sensorial na produção de refeições. Nutr Pauta. 2005; 13(75):4-17.

20. Veiros, MB. Análise das condições de trabalho do nutricionista na atuação como promotor de saúde em uma unidade de alimentação e nutrição: um estudo de caso [mestrado]. Florianópolis: Universidade Federal de Santa Catarina; 2002.

21. Veiros MB, Proença RPC. Avaliação Qualitativa das preparações do cardápio de uma unidade de alimentação e nutrição. Nutr Pauta. 2003; 13(2):36-42.

22. Hirsch KM, Hassanein RS, Wutrecht CL, Nelson SJ. Factors influencing plate waste by hospitalized patient. J Am Dietet Assoc. 1997; 75(3):270-3.

23. Stephen $A D$, Beingg $C L$, Elliot ET, Macdonald $I A$, Allison SP. Food provision, wastage and intake in elderly hospital patients. Proc Nutr Soc. 1997; 56(2): 220A.

24. Kelly L. Audit of food wastage: differences between a plated and bulk system of meal provision. J Hum Nutr Dietet. 1999; 12:415-24. doi: 10.1046/j.1365-2 77x.1999.00183.x.

25. Corrêa TAF, Soares FBS, Almeida FQAA. índice de resto-ingestão antes e durante a campanha contra o desperdício, em uma Unidade de Alimentação e Nutrição. Hig Aliment. 2006; 20(140):64-73.

26. Santos MMK, Oliveira AR, Pousada Gómez CHM, Piekarczyk SMS, Shimokomaki M. Aplicação da gestão de qualidade no restaurante universitário da Universidade Estadual de Londrina: desperdício de alimentos. Hig Aliment. 2005; 19(137):21-4.

27. Brito RP, Berardi PC. Vantagem competitiva na gestão sustentável da cadeia de suprimentos: um metaestudo. Rev Adm Empresa. 2010; 50(2):155-69.

Recebido em: 17/9/2010

Versão final reapresentada em: 21/12/2010 Aprovado em: 11/4/2011 